\title{
A evolução do conceito de trabalho e sua relação com o desenvolvimento econômico
}

\author{
Francisco Alves Queiro₹. \\ Laumar Neves de Soura ${ }^{2}$
}

Resumo: O presente artigo tem como objetivo analisar historicamente as relações da categoria trabalho e desenvolvimento econômico, a evolução do conceito de trabalho, bem como a transição do trabalho escravo para o assalariado. Para tanto, realizou-se um estudo bibliográfico que descreve os aspectos conceituais do trabalho fundamentado no prisma marxista. A pesquisa parte da premissa de que a capacidade produtiva da sociedade está aliada ao uso do trabalho como mercadoria e que a classe burguesa produz riqueza via exploração do trabalhador. O investimento no trabalhador não acompanha o processo de incorporação de progresso tecnológico às máquinas e equipamentos, e isso promove um desequilíbrio estrutural na sociedade. O acúmulo de riqueza ocorreu, primeiramente, entre a nobreza e o clero, depois, na classe burguesa capitalista. A sociedade e o Estado devem se empenhar em produzir um mercado de trabalho menos fragmentado, com a ampliação das relações assalariadas, sujeitas à proteção social e à homogeneização das condições de trabalho. Segundo a pesquisa, um dos fatores principais para o efetivo desenvolvimento é a criação de emprego, com remuneração que permita a manutenção das condições essenciais à vida.

Palavras-chave: Desenvolvimento socioeconômico. História. Trabalho.

Abstract: This article aims to analyze historically the relations of the labor category with economic development, its transition from slave to wage labor and the evolution of its concept. To this end, a bibliographical study was conducted, which describes the conceptual aspects of the work from the Marxist prism. The research starts from the premise that the productive capacity of society is allied to the use of labor as a commodity and that the bourgeois class produces wealth via the exploitation of the worker. Investment in the worker does not accompany the process of incorporating technological progress into machinery and equipment, and this promotes a structural imbalance in society. The accumulation of wealth was primarily by the nobility and clergy, and now by a capitalist bourgeois class. Society and the state must strive to produce a less fragmented labor market, with the amplification of wage relations, subject to social protection and the homogenization of working conditions. It considers that one of the main factors for effective development is job creation, with remuneration that allows the maintenance of essential conditions for life.

Keywords: Socioeconomic development. Story. Job.

\footnotetext{
${ }^{1}$ Doutor em Desenvolvimento Regional e Urbano pela Universidade Salvador (UNIFACS), Laureate International Universities. Professor da Faculdade Adventista da Bahia (FABDA) e professor substituto da Universidade Federal do Recôncavo da Bahia. E-mail: professor@franciscoqueiroz.com.br.

2 Doutor em Ciências Sociais pela Universidade Federal da Bahia (UFBA). Professor da Universidade Salvador (UNIFACS), Laureate International Universities. E-mail: laumar.souza@gmail.com.
} 


\section{Introdução}

O presente artigo representa mais uma contribuição para a compreensão do conceito de trabalho, dialoga historicamente sobre sua função no processo do desenvolvimento das forças produtivas e dos modos de produção. Parte da premissa de que a capacidade produtiva do trabalho, aliada à expansão da renda real do trabalhador ocupado e à incorporação de progresso tecnológico nos processos produtivos são as bases para o desenvolvimento socioeconômico.

Nesta discussão, o propósito foi, seguindo uma linha marxista, desvendar as verdadeiras relações entre trabalho, capital e desenvolvimento na sociedade capitalista. Admite-se a existência de outra vertente, as concepções de Max Weber, dos economistas liberais fundadas nas teorias de Smith e de David Ricardo - Escola Clássica, os quais se propuseram estudar e definir padrões e modelos de organização e desenvolvimento da sociedade para a produção capitalista. Essa é uma vertente cujo objetivo foi harmonizar forçadamente os conflitos entre trabalho e capital, desconsiderando ou minimizando a existência antagônica das classes sociais ${ }^{3}$.

Antes de entrar na análise da categoria trabalho pela vertente escolhida, julga-se prudente discorrer sobre as concepções liberais, uma vez que se considera a sua importância. Adam Smith publicou seu livro em 1776, o primeiro pensador a apresentar o trabalho como geração de valor, em uma vertente econômica, segundo a qual o trabalho está na base da produção de riqueza do modo de produção capitalista. Esse autor não demonstrou preocupação com o desemprego e acreditava que o mercado desregulado, sob a égide da denominada mão invisivel, poderia equilibrar os salários e a oferta de postos de trabalho. Ricardo publica suas ideias em 1817, moderniza as concepções de Smith e estabelece uma Teoria do Valor Trabalho, a qual define que as mercadorias, em uma economia capitalista, devem ser trocadas na proporção da quantidade de trabalho que apresentam. $\mathrm{O}$ valor vem do custo de trabalho incorporado à mercadoria. Ricardo divide o trabalho em duas partes, o imediato, ação humana direta para produzir algo, e o mediato, que se refere ao trabalho incorporado às máquinas. Também acredita na desregulação do mercado como mecanismo de manter equilíbrio entre o emprego e desemprego. Sem se preocupar com as condições de vida do trabalhador, afirmou que os salários deveriam ser mantidos para subsistência dos trabalhadores.

Constatado que a interpretação liberal trata a categoria trabalho de maneira meramente econômica, e que não há uma preocupação com a efetiva melhora das condições vida do trabalhador, optou-se por fazer uma discussão sobre um referencial teórico mais filosófico e sociológico, que concebe o trabalho como categoria fundante da sociedade. Para essa empreitada, recorreu-se a estudos de Marx, Lucáks e seus precursores: Harvey, Francisco Oliveira, Celso Furtado, Milton Santos, Ricardo Antunes e Márcio Pochmann.

\footnotetext{
3 Tais crenças se fundamentaram na interpretação do pensamento de Gramsci, Hannah Arendt e István Mészáros, em debate com os professores Alfredo da Mata e Celso Antonio Fávero, da UNEB.
} 
As leituras de Marx e Lucáks ${ }^{4}$ permitiram compreender que o trabalho é a relação social que altera a vida do sujeito e do meio ambiente. Harvey (1982) complementa esse entendimento ao dizer que o trabalho garante ao homem a sobrevivência e a evolução, o trabalho modifica o espaço e transforma a natureza primitiva em natureza construída. É o principal mecanismo de integração social, além de ser fator relevante ao processo de reprodução e acumulação capitalista, elemento primário de todas as formas de desenvolvimento.

O objetivo deste artigo é, precisamente, analisar de que maneira a categoria trabalho transitou pelos modos de produção até se consolidar como assalariado, e sua relação com o desenvolvimento econômico da sociedade. Consiste em um estudo bibliográfico, que descreve os aspectos conceituais do trabalho, discorre sobre os aspectos históricos do trabalho nos modos de produção, de como passou de escravo, servil, para trabalho remunerado. Por essa via, apresenta-se uma compressão da categoria trabalho segundo uma concepção sociológica e econômica, inserido na ciclidade da História. Assim este artigo conclui que o trabalho é o agente efetivo do desenvolvimento socioeconômico de um país.

\section{Traços históricos das relações de trabalho: escravo, servil e assalariado}

Para compreender o conceito de trabalho aceito neste texto, segundo o qual, o homem é um ser social, transforma a natureza primitiva e essa natureza transformada modifica as relações sociais e o próprio homem, é necessária uma breve descrição histórica dos modos de produção para compreender a evolução das relações de trabalho, desde o sistema escravista até ao assalariado ${ }^{5}$. Com base nisso, é possível visualizar de que maneira a revolução industrial consolidou o capitalismo e as relações de trabalho remunerado.

Os modos de produção referem-se à forma como as forças produtivas de uma sociedade e suas relações de produção estão organizadas socioeconomicamente, ou seja, diz respeito a como a riqueza se organiza e se distribui. O primeiro modo de produção que se pode observar na humanidade é o primitivo, uma formação econômica e social que predominou por centenas de milhares de anos. Os homens basicamente não produziam seus alimentos, trabalhavam em conjunto, caçavam, pescavam, colhiam frutos na natureza e dividiam tudo coletivamente, não existia Estado nem propriedade privada e as terras e os meios de produção pertenciam a todos. Esse modo predominou até o homem iniciar o processo de produção de bens para consumo e adotar o conceito de propriedade. Desse momento em diante, algumas tribos começaram a desejar as terras e as riquezas das tribos vizinhas e, assim, começaram as guerras. Saqueados e explorados, os vencidos eram transformados em escravos, produzindo alimentos e bens para os seus senhores. O escravo não era dono de nada, nem do seu próprio corpo, era considerado uma coisa, tal qual uma ferramenta, gados e lotes de terras pertencentes ao seu senhor.

\footnotetext{
4 "O trabalho é um processo entre atividade humana e natureza: seus atos estão orientados a transformar objetos naturais em valores de uso” (LUCÁKS, 2011, p. 47).

${ }^{5}$ Robert Castels, ao observar a grande difusão do salário, constrói o "conceito de sociedade salarial”, resultante da relevância social do fator salário na identificação e participação do trabalhador (CASTELS, 2015).
} 
O modo escravista surgiu como atividade econômica no Egito, mas foi juridicamente garantido como modo de produção dominante na antiga Grécia, Séc. V a.C, com o surgimento e organização do Estado (ROSSI, 2005). Posteriormente, foi difundido mais amplamente pelo Império Romano. Paralelamente, de maneira muito similar aos métodos do modo de produção escravo, pôde-se observar o modo de produção asiático predominante na China, Índia, Egito e parte oriental da África. Na sociedade, e dentro desse modo de produção, existia certa hierarquia, composta pelo Estado, por nobres (os senhores), camponeses (teoricamente, homens livres) e escravos, os quais produziam e, se necessário, guerreavam para manter a riqueza e a grandeza de seus nobres. Os modos de produção tinham como geração de riqueza a exploração do trabalho escravo, condição predominante na Europa até a queda do Império Romano (século IV d.C). A crise do modelo escravista romano, aliado ao movimento migratório germânico dessa época, ao unir os saberes e costumes dessas duas culturas, abriu espaços para um processo de grandes transformações econômicas, políticas e sociais na sociedade europeia. Surgiu, assim, o modo de produção feudal, que exercia práticas de colonato, clientela, servidão e unidade de produção autossuficiente.

No sistema feudal, o camponês realizava um trabalho compulsório (obrigatório) nas terras do senhor feudal, ao qual pagava pelo arrendamento e cultivo das terras onde morava, independentemente de quanto produzia. Apesar de rudimentares, as forças produtivas, as ferramentas e técnicas de trabalho eram de propriedade dos trabalhadores, os quais, no entanto, estavam presos a terra e não podiam difundir suas técnicas ou, simplesmente, sair de onde trabalhavam. A relação de servidão se realizava de três formas. $\mathrm{Na}$ primeira, o senhor feudal apropriava-se da renda-trabalho (Córveia), horas de trabalho que o servo teria que prestar nas terras do senhor feudal; na segunda, renda-espécie, os servos eram obrigados a ceder parte de sua produção e, na terceira, a renda-dinheiro, o servo tinha a obrigação de comercializar sua produção para conseguir dinheiro, ouro ou prata para realizar o pagamento ao seu senhor. Além dessas apropriações, podem-se citar diversas taxas obrigatórias a serem pagas pelos camponeses, a exemplo de taxa de casamento e taxas à Igreja Católica (DOBB, 1980).

Nesse estágio de desejo pelo dinheiro desenvolveu-se uma série de práticas e inovações tecnológicas na produção. Entre as práticas, o desenvolvimento do sistema de empréstimos e, por consequência, o bancário, a aplicação de técnicas para o desenvolvimento e ampliação da produção de alimentos e dos artefatos. Para isso, novas terras e mais trabalhadores foram incorporados à produção agrícola. Mas o crescimento da produção ocorria em velocidade maior do que a reprodução populacional dos servos. Essa escassez de mão de obra levou os senhores a pagar por contratação de trabalho temporário. Tais medidas fragilizaram as relações servis e começaram a construir uma força de trabalho independente. Paralelo a esse movimento, as atividades urbanas, antes incipientes, passaram por significativas mudanças em virtude da ampliação do comércio dos produtos oriundos dos excedentes e da própria necessidade da nova vida urbana que se ampliava. Além de atender às necessidades agrícolas, o trabalho passou a atender às demandas da produção para o mercado (HUBERMAN, 1981).

No século XI, com a diminuição das guerras, melhoria das condições de vida e crescimento da população, ampliou-se o mercado de bens e serviços, forçando maior produtividade, melhor organização 
da atividade comercial e política, estruturação da moeda, do crédito e estrutura das cidades. Foram seis séculos de avanços da atividade mercantil, intelectual e política, confrontando com a estrutura feudal. À medida que as forças produtivas avançavam, aumentava o trabalho pago, a difusão dos mercados, da expansão marítima, da cultura e de novas ideias econômicas, enfim, o espaço econômico do feudalismo, até então predominante, cedia lugar às forças capitalistas, tendo como ápice a Revolução Industrial Inglesa, no século XVIII. O trabalho, tema cerne deste artigo, outrora escravo e servil, no novo modo de produção, passa a ser assalariado.

A transição do feudalismo para o capitalismo teve como pano de fundo grandes movimentos sociais. O primeiro a contribuir para a mudança é o de renovação da Igreja Católica, com as primeiras formações dos Estados nacionais ${ }^{6}$, séculos XIII e XIV. Com a organização das nações, surgiram grandes conflitos entre o Estado e os senhores feudais, por exemplo. Nessa época, houve também confrontos de interesses dentro da própria Igreja, entre o papado e os reis dos novos estados. Movimentos de oposição a favor de reformas na Igreja emergiram, principalmente, na França e se espalharam por toda a Europa. A revolta dos camponeses foi impulsionada por guerras, epidemias, corrupção, arbitrariedades e pela vontade de liberdade de expressão e de estudar os ideais do renascentismo. A tradução da Bíblia para outros idiomas, principalmente para o Alemão, por Martinho Lutero (1483-1546), difundiu ideias humanistas e modernas, contrárias às indulgências e aos abusos da Igreja Católica. Essa conjunção de fatos denominou-se Reforma Protestante.

Outro movimento que serviu de lastro para implementação do modo de produção capitalista foi, de ordem cultural, o Iluminismo, que se desenvolveu principalmente na Inglaterra, Holanda e França, nos séculos XVII e XVIII, e deu origem aos ideais de liberdade política e econômica, uma das bases do capitalismo. O precursor foi o matemático René Descartes, (1596 - 1650), que valorizava a razão e criticava o absolutismo, o mercantilismo e o clero. Os pensadores iluministas contribuíram para avanços em diversos ramos das ciências e da sociedade, mas, como o tema central desta análise é a evolução histórica das relações de trabalho - que começa a se apresentar como trabalho remunerado nesse momento da história —, destacam-se, neste momento, os seguintes pensadores: a) John Locke (16321704), que defende a Teoria do Governo Limitado, as garantias dos direitos naturais, o direito à vida, à felicidade e à propriedade. A proposta de Locke é que, se o governo abusasse do poder, deveria ser substituído (FILHO, 1993). b) Voltaire (1694-1770), um dos maiores filósofos iluministas e grande crítico do regime feudal, do mercantilismo e da Igreja, defendeu a liberdade de pensamento e de expressão; c) Montesquieu (1698-1755), que propunha a divisão do poder do Estado em executivo, legislativo e judiciário; d) Rousseau (1712-1778), um dos poucos a criticar a burguesia e a propriedade privada, chamou atenção à desigualdade e aos conflitos sociais, pois propunha que a vontade do povo determinasse as decisões políticas.

Fortemente inspirado pelos ideais iluministas, a população francesa se revoltou contra o governo de Luiz XVI, em um levante popular liderado pela burguesia local, denominado Revolução Francesa

\footnotetext{
${ }^{6}$ Os primeiros estados nacionais a serem formados foram Portugal e Espanha. Logo depois, França e Inglaterra e,
} em seguida, a unificação da Itália e da Alemanha (Portal Educação, 2019). 
(1789). A Revolução tomou o poder do rei e o passou a uma Assembleia Constituinte, que suprimiu as leis feudais, retirou os privilégios do clero e da nobreza, proclamou a Declaração dos Direitos do Homem e do Cidadão, na qual estabelecia a liberdade e defendia a ideia de que todos eram iguais perante a lei e promulgou a primeira Constituição francesa, 1791 (FURET, 1989).

A Reforma Protestante, o Iluminismo, a Revolução Francesa, os pensamentos econômicos de Quesnay (1694 - 1774), Adam Smith (1723-1790), Thomas Robert Malthus (1766 - 1834) e David Ricardo (1772 - 1823) foram os pilares da construção do Liberalismo econômico, corrente teórica que alicerçou a Revolução Industrial, que teve sua primeira fase entre 1760-1860 na Inglaterra com o tear mecânico nas indústrias de algodão. Assim, edificou-se o trabalho pago.

Desde as transformações provocadas pelas grandes revoluções, o trabalho por salário tornou-se uma situação, em certa medida, protegida pelo direito, um compromisso social e jurídico ordenado aos Estados. Com a nova organização do Estado, o clero e os senhores feudais perdem o protagonismo no exercício do poder e começa a prevalecer a burguesia industrial, trazendo consigo uma concepção de comunidade livre e autônoma. Ademais, os indivíduos passam a ser tratados como cidadãos. De homem com direitos, cidadão e livre, observa-se, portanto, a nova organização do processo de trabalho, desenvolvido em paralelo com o capitalismo.

Contudo, os frutos dos avanços sociais conseguidos pelas grandes reformas e revoluções não foram repartidos de maneira igualitária por toda a sociedade. A maior parte dos lucros e benefícios da nova ordem econômica foi absorvida pelos donos do capital - a burguesia. Os avanços produtivos e a mecanização dos processos retiraram os meios de produção dos trabalhadores, os quais, a partir desse instante só teriam sua mão de obra para ofertar, não produzem mais para si, e sim para os donos dos meios de produção. O trabalho passou a ser considerado, portanto, uma mercadoria, um instrumento do processo de produção e, como tal, pensado para se extrair o máximo de produtividade possível. Uma das primeiras grandes concepções organizativas do trabalho foi a divisão do trabalho de Adam Smith, que separou o homem da compreensão do processo total da mercadoria que produzia. Dividiu as tarefas com foco na eficiência produtiva e na possibilidade de troca do trabalhador como se fosse uma engrenagem, especializou o homem em tarefas simples e rotineiras para se extrair a produção o mais rápido possível. As habilidades manuais, antes valorizadas perdem espaço para a eficiência da maquinaria, o homem precisa alimentar e monitorar o funcionamento das linhas de produção.

Marx (1993) chamou esse processo de perda de meios de produção e alienação do trabalho, e observa que isso promoveu a divisão do trabalho em manual e intelectual. Os trabalhadores são, assim, distribuídos de acordo com suas aptidões físicas, o processo industrial foi desenhado no intuito de alocar de maneira mais eficiente possível os homens às máquinas, ou às maquinas aos homens, em um processo histórico mais adiante, a partir dos anos de 1950. Ambos os processos eram, no entanto, a combinação máquina - homem - tempo, tendo o trabalhador a concepção de instrumento de trabalho e não de ser social e produtivo que gera valor.

Após essa necessária descrição da evolução das relações de trabalho, perpassando pelos modos de produção até o século XX, percebe-se que as mutações das relações produtivas, desde a escravidão, 
mantêm a exploração da grande massa que, efetivamente, produz valor: os trabalhadores. Inicialmente, os nobres e o clero apropriaram-se da riqueza e, agora, a classe burguesa capitalista. Na contemporaneidade, um fato importante a se observar é que o empresariado burguês encontra no Estado moderno um aparato jurídico legal para ordenar os salários baixos e as condições precárias de trabalho, em favor do dito necessário crescimento econômico e ordem pública.

\section{Notas sobre o conceito de trabalho}

O debate sobre o tema trabalho na idade média, século IV a XVIII, foi incipiente, de modo que o escravismo, o autoritarismo religioso e o absolutismo exerceram práticas de inibição à Filosofia e à Ciência. Esse período foi marcado por execuções, prisões e queima de diversas obras, inclusive bibliotecas inteiras, e a repressão a quem questionasse o sistema social vigente ${ }^{7}$ era brutal. Assim, há uma enorme lacuna temporal e intelectual sobre o tema e, somente a partir de 1800, Georg W. F. Hegel, na obra $A$ Filosofia do Direito (1985), apresenta um conceito de trabalho (Arbeit) em uma perspectiva econômica e filosófica que Lucáks (2011) chama de formadora de consciência. Isso contribui para os estudos de Marx, que, ao observar o tema com base na atividade humana básica (QUINTANEIRO, 2003), se torna um dos mais importantes estudiosos sobre a categoria trabalho.

Os manuscritos de Marx de 1844, publicados oitenta anos depois de sua morte, trazem o que ele denomina Filosofia da Práxis, cuja categoria central é o trabalho humano, uma atividade prática sensível que provê as necessidades cotidianas e naturais e, muito mais, constrói o homem enquanto ser social. O homem como resultado de sua atividade produtiva “é obra de suas próprias mãos” (MARX, 2011, p. 15), que nasce ao engendrar o mundo do trabalho, a história e a cultura. Marx extrai a base dessas conclusões de Hegel, a quem atribui a responsabilidade de ser o primeiro pensador a apreender a essência do que é trabalho e, com base nisso, avançar e derivar outros conceitos relevantes (alienação, exército de reservas, mais-valia, apropriação) que, até hoje, explicam a realidade do trabalho no modo de produção capitalista. No livro Formações econômicas pré-capitalistas, Marx (2011, p. 65) declara:

Um dos pressupostos do trabalho assalariado e uma das condições históricas do capital é o trabalho livre e a troca de trabalho livre por dinheiro, com o objetivo de reproduzir o dinheiro e valoriza-lo; de o trabalho ser consumido pelo dinheiro [...] como valor de uso para o dinheiro. Outro pressuposto é a separação do trabalho [...] do meio material do trabalho.

No processo de trabalho criam-se os frutos da atividade produtiva, porém, os objetos criados pelo trabalhador são propriedade exclusiva do capitalista. À medida que aliena sua mão de obra como

\footnotetext{
$7 \mathrm{Na}$ dinastia de QIN, a China, queimou todos os livros contrários à ideologia dominante; no cristianismo, os inquisidores instaurados e reis absolutistas exerceram a mesma prática, Constattino 325 d. C.; C Atanasio de Alexandria, 367 d.C. ; o bispo Cirilo queimou a biblioteca de Alexandria em 435 d.C.; Recaredo I na Espanha, 586 d.C. Manuscritos Judaicos em 1244 em Paris; inquisição Espanhola 1499; enfim, as inquisições católicas queimaram livros na américa, manuscritos maias, 1560, na Alemanha, 1640, na Áustria 1730. Essa prática de imposição da ideologia por queima de produções teóricas filosóficas contrárias ao sistema vigente continuou, mesmo no século XX, adotadas por regimes autoritários na Europa, Hitler e Mussoline, e na América, com destaque para o Chile e os Estados Unidos. (QUINTANEIRO, 2003).
} 
mercadoria, o trabalhador afasta-se do resultado do seu trabalho e, na maioria das circunstâncias, não reconhece que o objeto criado é o produto do seu próprio trabalho. Para Marx (2009, p. 80),

O trabalhador se torna tanto mais pobre quanto mais riqueza produz, quanto mais a sua produção aumenta em poder e extensão. $\mathrm{O}$ trabalhador se torna uma mercadoria tão mais barata quanto mais mercadoria cria. Com a valorização do mundo das coisas (Sündenfall) aumenta em proporção direta a desvalorização do mundo dos homens (Menschenwelt). O trabalho não produz somente mercadorias; ele produz a si mesmo e ao trabalhador como uma mercadoria, e isto na medida em que produz, de fato, mercadorias em geral.

$\mathrm{Na}$ análise das obras de Smith e Ricardo, Marx avança sobre as concepções da categoria trabalho. Adam Smith publicou seu livro em 1776 e é o primeiro pensador a apresentar o trabalho como geração de valor, segundo uma vertente econômica e que está na base da geração de riqueza do modo de produção capitalista. É importante destacar que essa obra inaugura o campo da Economia como ciência. Ao se afastar da fisiocracia, doutrina segundo a qual a riqueza se concentrava nas terras, o autor considera o trabalho o eixo fundamental para o crescimento econômico, principalmente com a divisão do trabalho, pedra fundamental de sua análise. Em A Riqueza das Nações, a preocupação de Smith consiste em criticar o mercantilismo, com o intuito de impulsionar o desenvolvimento do pensamento liberal.

Marx afirma que, além de não demonstrar preocupação com o desemprego involuntário, Smith confunde valor de troca com o valor trabalho. E considerou um equívoco as principais crenças de Riquezas das Nações: 1) o mercado desregulado, sob a égide da mão-invisivel, poderia gerar o equilíbrio nos salários e na oferta de postos de trabalho; 2) a divisão do trabalho era um mecanismo de desenvolvimento da sociedade. Marx (2017, p. 67) acredita ainda que "um homem que passa toda a vida a desempenhar algumas operações simples [...] não tem a oportunidade de exercer a inteligência [...] torna-se estúpido e ignorante [...] a subdivisão do trabalho é o assassinato de um povo". A divisão do trabalho cria riqueza para o capitalista e não para o trabalhador, pelo contrário, é alienante ao homem, pois tira deste a capacidade de compreender o processo produtivo e permite ao capitalista apropriar-se da riqueza produzida em razão do trabalho.

Smith define o trabalho como a fonte e a medida do valor de troca, teoria que, segundo Marx, é limitada e imprecisa. Ricardo publica suas ideias em 1817, vai mais adiante e moderniza as concepções de Smith no campo da Economia. Por outro lado, estabelece uma concepção também simplista da teoria do valor trabalho, "o valor de uma mercadoria [...] depende da quantidade relativa de trabalho que é necessária para sua produção e não da maior ou menor compensação que é paga por aquele trabalho" (GRESPAN, 2019, p. 60).

Para Marx, Ricardo não tem a dimensão social da categoria trabalho, pois julga que o valor vem do custo de trabalho relativo incorporado à mercadoria. Ricardo divide o trabalho em duas partes: o imediato, ação humana direta para produzir algo, e o mediato, que se refere ao trabalho incorporado às máquinas. E limita-se a afirmar que o valor do trabalho é definido apenas pela produção. Marx acredita que isso também é impreciso, pois o trabalho não é simplesmente uma mercadoria a ser trocada, "a determinação do valor pelo tempo do trabalho produtor da mercadoria constitui, portanto, um nível 
"interno" que "aparece" num nível externo, no da concorrência ou da circulação das mercadorias, como algo interior que se manifesta" (GRESPAN, 2019, p. 62).

A discordância de Marx (2011) está também no fato de Ricardo acreditar na desregulamentação do mercado como um mecanismo para manter um equilíbrio entre o emprego e desemprego, além de não se preocupar com as condições de vida do trabalhador, principalmente quando afirma que os salários deveriam ser mantidos no nível de subsistência dos trabalhadores.

Marx (2011) afirma que David Ricardo não consegue avançar na definição da Teoria do Valor Trabalho, pois confunde valor do trabalho com preço. Ao utilizar em seus estudos as concepções da Teoria do Valor, Marx parte do pressuposto de que a produção econômica é uma atividade coletiva, portanto, define-se o valor de uma mercadoria com base na quantidade média de horas de trabalho empregada, incluindo aí o trabalho anterior destinado a produzir as máquinas e matérias-primas. Assim, o preço de uma mercadoria deve considerar a quantidade de trabalho nela incorporada.

Os clássicos concebem a Teoria do Valor fundamentados em princípios simplistas, segundo os quais, o trabalho é um mero produto, como outra mercadoria qualquer, e pode ser trocado. Faz-se, portanto, uma confusão com o valor de troca. Marx diverge dessa opinião, pois julga que apenas o trabalho é o elemento portador de valor e somente o trabalho humano vivo tem a capacidade de criar valor/riqueza. Uma melhor compreensão dessa afirmação está na explicação de Mattei (2003): “O elemento decisivo é o trabalho social, tendo em vista que o valor da força de trabalho corresponde ao tempo de trabalho socialmente necessário à sua reprodução, sendo justamente o trabalho social total o responsável pela geração da massa de valor que é repartida entre o capital e o trabalho".

A leitura das obras de Hegel serviu de fundamento metodológico e filosófico para Marx aperfeiçoar as concepções sobre a categoria trabalho. Segundo Lessa (2015, p. 21), Hegel é o primeiro autor a declarar que História "é um processo, o passado determina o presente e o presente determina o futuro". Com base nisso, Marx declara que a história começa quando o homem deixa de ser coletor e passa a ter uma relação com a natureza típica de um ser social: o trabalho. O homem começa, portanto, a transformar o meio ambiente para sobreviver. Marx afirma, ademais, que o trabalho se constrói primeiro na consciência e depois se materializa no mundo objetivo. O ser social institui-se por meio do processo de trabalho, de modo que o indivíduo desenvolve capacidades e habilidades que originarão as Ciências, as Artes e as Ideologias e, nessa consideração, Marx considera o trabalho uma categoria fundante da sociedade.

Seguindo o prisma marxista, chega-se a Lucáks, um dos mais importantes teóricos na conceituação moderna de trabalho. Sua obra é bastante vasta e discutida em diversos artigos científicos, trata-se de uma referência nas teses de doutorado sobre o tema. Em O trabalho: ontologia do ser social, Lucáks observa um momento histórico extremamente relevante para compreender a significância do trabalho, as circunstâncias em que o homem supera a existência "animalesca", a situação de "animal que fabrica ferramentas" e, muito mais que isso, aquele que constrói e usa instrumentos e passa a ter o "domínio sobre si mesmo". O filósofo chama esse instante de "autocriação do homem como homem", momento 
em que surge um novo ser: o social. O autor complementa: "Esse também é um momento do salto a que nos referimos, da saída do homem da existência meramente animalesca” (LUCÁKS, 2011, p. 46).

Lucáks discute o trabalho em uma perspectiva ontológica, da natureza do ser, da existência da própria realidade. Com uma base teórica hegeliana e marxista, afirma que uma das categorias estruturantes da sociedade é o trabalho, cujos traços são os estágios do desenvolvimento humano quando assume a forma de produção social, (práxis) interação entre o homem e a natureza (LUCÁKS, 2011, p. 43).

Sobre as leituras que fez sobre Lucáks e Marx, Ricardo Antunes afirma que o capitalismo visa à criação de uma riqueza para ser privada e acumulada e, por isso, destrói a força de trabalho, o meio ambiente e segrega a sociedade. $\mathrm{Na}$ apresentação de seu clássico livro Os sentidos do trabalho, assevera que o trabalho exerce um processo contraditório na vida do homem “[...] emancipa e aliena, humaniza e sujeita, libera e escraviza" e nos convida a estudar o trabalho humano como uma "questão crucial no mundo" (ANTUNES, 2009, p. 12).

Após essa discussão histórico-conceitual, é importante reafirmar o papel e o que se compreende do trabalho neste artigo: o trabalho concebe o homem na condição de ser social, transforma a natureza primitiva - o homem passa a transformar o meio ambiente para a sobrevivência - e essa natureza transformada modifica as relações sociais e o próprio homem - o trabalho é a relação social que altera a vida do sujeito e do meio ambiente - é o principal mecanismo de integração social.

\section{O trabalho como agente efetivo do desenvolvimento econômico: o trabalho é que gera riqueza}

Nesta seção, o propósito é discutir as relações da categoria trabalho com o processo de desenvolvimento socioeconômico de um país. A riqueza vem do trabalho, uma sociedade com altos índices de ocupação produtiva, remunerada e decente consegue realizar a produção capitalista (consumo) e manter os níveis crescentes de desenvolvimento de um país. Keynes (1986) demonstra tal percepção em seu famoso livro A Teoria Geral do emprego, do juro e da moeda, em 1939, principalmente ao afirmar que os governos devem se preocupar em criar e manter postos de trabalho, no intuito de sair das crises econômicas.

Nas análises sobre o processo de produção do capital, Marx (1986) aponta um grande problema acerca da geração de postos de trabalhos. A obra O Capital, publicada em 1867, mostra que a incorporação de progresso técnico ao processo produtivo é muito mais acelerado nas máquinas e equipamentos do que na qualificação de mão de obra. Essa questão confronta com a necessidade de aumento de pessoal ocupado e da renda em uma sociedade capitalista, ou seja, uma tendência natural é reduzir a ocupação. Em nenhum momento Marx propõe alternativas ao sistema capitalista, no entanto, suas conclusões mostram que a sociedade deve promover ajustes contínuos no processo produtivo para reequilibrar os investimentos na força de trabalho.

Oliveira (2015) declara que, nos países capitalistas centrais, EUA e Europa, o processo de produção e incorporação tecnológica ocorreu segundo uma dinâmica que promoveu uma significativa absorção da força de trabalho. No entanto, mesmo nesses países, esse processo não tem sido 
historicamente homogêneo, pois, em outro período, há registros de momentos de instabilidades e desocupações. Nos países periféricos, a exemplo dos localizados na América Latina, a produção e incorporação tecnológica ocorreram em uma estrutura social bem mais desigual. Furtado (2005) chamou esse processo de "imitativo" e dependente; Pochmann (1986), de capitalismo tardio. Tais características tornaram ainda mais desafiadora a tarefa de construir uma camada de trabalhadores ocupados com capacidade de renda e acumulação capazes de contribuir para o desenvolvimento econômico desses países.

Nesse sentido, Oliveira (2015) chama atenção para o fato de que os países periféricos foram condicionados a uma posição de papel auxiliar no processo de desenvolvimento e acumulação dos países centrais. Oliveira (2015, p. 41) declara que, nos países periféricos:

[...] o processo de modernização concentrou-se na agricultura exportadora, com pouca capacidade de irradiação dos benefícios da maior produtividade para os demais setores da atividade econômica. Como contrapartida, configurou-se uma estrutura produtiva espacialmente delimitada, comumente instalada em regiões próximas às áreas costeiras, e que, por esse motivo, urbanizaram-se velozmente, ao tempo que estabeleciam ligações tênues com o interior do território nacional. [...] Nesse sentido, o estilo de desenvolvimento que prevaleceu no capitalismo periférico aliou a implantação de uma estrutura econômica voltada para a oferta de bens e serviços característicos da civilização industrial europeia, com uma distribuição da renda altamente concentrada no topo da estrutura distributiva.

Para avançar na compreensão das relações entre trabalho e desenvolvimento, cabe destacar que o modelo periférico é concentrador do resultado do processo produtivo e impõe, diante da citação de Oliveira, dificuldades na absorção de força de trabalho. Tal condição se agrava aliada a duas outras características: 1) a fragilidade na regulação das relações de trabalho entre empregado e empregador; e 2) o crescimento populacional foi, nos últimos cinquenta anos, proporcionalmente muito maior do que a capacidade de oferta de postos de trabalho.

É necessário admitir a diferença entre desenvolvimento e crescimento econômico, visto que um não é sinônimo do outro. A acumulação de capital pelos detentores dos meios de produção (crescimento) pode ocorrer de forma bastante discrepante da melhoria das condições de vida da sociedade. Considera-se desenvolvimento econômico uma derivação dos conceitos de Celso Furtado (1974) e Francisco de Oliveira (2011): o conjunto de transformações estruturais econômicas, políticas e sociais que permitam o aumento do nível de produtividade e da renda média dos trabalhadores.

É importante também compreender a explicação de Celso Furtado de que um país subdesenvolvido ou em desenvolvimento não necessita copiar modelos de desenvolvimento de um país desenvolvido, mas verificar em suas potencialidades, fundamentados em sua realidade e especificidades, o caminho para crescer e se desenvolver. No famoso livro O mito do desenvolvimento, Celso Furtado (1974) chama de ilusão querer construir um projeto de desenvolvimento reproduzindo modelos de países que se autodenominam desenvolvidos e fazem propostas de reformas estruturais necessárias ao país.

O desenvolvimento econômico e o trabalho têm uma relação indissociável. Esse debate está presente nas proposições de Francisco Oliveira, Celso Furtado e Paul Singer, os quais enfatizavam o 
pensamento marxista de que "o desenvolvimento econômico era a causa última do desenvolvimento social",

Marx constata que os meios de produção e a acumulação capitalista se multiplicam em velocidades muito superiores e desproporcionais à remuneração dos salários e à oferta de postos de trabalho e isso constituía um viés para o desenvolvimento social e econômico.

Outro importante teórico, defensor da concepção de que o desenvolvimento de uma sociedade efetiva-se em razão do bem-estar social, e não do crescimento econômico, é o indiano Amartya Kumar Sen, prêmio Nobel de Economia (1998), professor emérito da Universidade de Cambridge, considerado o "pai do IDH", em 1990, ao lado do paquistanês Mahbub ul Haq. Amartya Sen, como é mais conhecido, principalmente pela obra "Desenvolvimento como Liberdade", considera que fatores sociais, como capacidade de consumo da população, educação e saúde, são importantes na quantificação do Desenvolvimento Humano. Sen defende que o Estado deve combater as desigualdades sociais, prestando serviços que possibilitem a construção de uma sociedade mais digna, com enfoque na educação, saúde e proteção das minorias. A relação direta entre trabalho, saúde, educação e desenvolvimento é amplamente defendida por Sen em "Pobreza e Fome: Um Ensaio sobre Direitos e Privação". Segundo essa obra, a fome não é causada somente pela falta, mas pela dificuldade de acesso aos alimentos. Em uma sociedade em que trabalhadores não conseguem comprar seus alimentos, existe fome mesmo com alimentos disponíveis (SEN, 1999).

O desenvolvimento econômico deve-se alicerçar em um processo de industrialização, modernização, incorporação de tecnologia, aproveitamento de conhecimento, mão de obra e recursos naturais para provocar mudanças positivas nas condições socioeconômicas e vidas dos trabalhadores. Trata-se de um processo dinâmico e efetivo. Keynes (1988) enfatiza que cabe ao Estado o processo indutor de criação e manutenção de postos de trabalho e que isso é condição para o desenvolvimento. Furtado (1988) observa que, apesar de ter muito mais riquezas, o Brasil é mais atrasado do que a Argentina, Chile, México e Uruguai. Então, há algo historicamente construído na produção do desemprego e da miséria. Cabe ao Estado, portanto, reparar e corrigir essa distorção.

Um país pode até crescer economicamente, mediante a expropriação de suas riquezas naturais, alienação e exploração de sua força de trabalho, mas, dessa forma, será um produtor de miséria social, de modo que o crescimento de países latinos e sul-africanos, conforme referencial citado neste artigo, alimentou o desenvolvimento de países centrais. No caso do Brasil, é necessário pensar em um modelo próprio, que aproveite suas riquezas naturais, desenvolva tecnologias próprias e crie internamente condições de absorção de mão de obra de forma decente, com capacidade de consumo.

Postos de trabalho decentes são fatores incondicionais para a manutenção do desenvolvimento econômico efetivo, mas são também consequências de uma série de outras medidas necessárias ao desenvolvimento de uma sociedade. Este artigo chama isso de condições estruturantes da produção, termo utilizado nos escritos do economista Fernando Pedrão, que considera a infraestrutura energética e

\footnotetext{
${ }^{8}$ Escritos do Socialismo Utópico ao Socialismo Científico (1833).
}

9 Índice de Desenvolvimento Humano (IDH) 
educacional elementos fundamentais para possibilitar o crescimento econômico, a geração de emprego e, posteriormente, a efetivação do desenvolvimento (PEDRÃO, 2005).

Fundamentado nos indicativos de Pedrão e na teoria de Celso Furtado, que utiliza a expressão 'condições necessárias para o desenvolvimento', este estudo compreende a necessidade de estudar a expansão do apontamento de Pedrão para cinco dimensões, as quais aqui se denominam condições estruturantes para o desenvolvimento econômico: a) infraestrutura energética; b) disponibilidade de potencial produtivo; c) infraestrutura educacional e tecnológica; d) infraestrutura logística; e e) infraestrutura monetária, política e jurídica. O desenvolvimento socioeconômico do Brasil poderá acontecer realmente quando forem perceptíveis no país políticas e ações que transformem positivamente tais dimensões.

\section{Considerações finais}

No decorrer da exposição a respeito da evolução das relações de trabalho, perpassando pelos modos de produção até a consolidação do capitalismo, percebe-se que a alternância nas relações produtivas, desde o período escravista, mantém a exploração da grande massa que, efetivamente, produz valor: os trabalhadores. $\mathrm{O}$ acúmulo de riqueza ocorreu inicialmente entre a nobreza e clero, e agora na classe burguesa capitalista, ou seja, entre os dominadores dos bens de produção que, por conta disso, obtiveram poder político e social. Um fato importante na contemporaneidade é que o empresariado burguês encontra no Estado moderno o garantidor de seus mecanismos de exploração, à medida que governos criam instrumentos jurídicos para validar a exploração da classe trabalhadora.

Neste artigo, realizou-se uma discussão histórico-conceitual sobre o papel do trabalho e de que maneira ele insere o homem enquanto ser social, transforma a natureza primitiva, modifica as relações sociais e o próprio homem, e configura-se como principal mecanismo de integração social.

Com base nos grandes autores clássicos citados, adota-se a premissa de que a sociedade e o estado devem-se empenhar para produzir um mercado de trabalho menos fragmentado, com a ampliação das relações assalariadas, sujeitas à proteção social e à homogeneização das condições de trabalho. Assim, é possível registrar avanços e retirar as pessoas das condições precárias de vida e trabalho, reduzir a exclusão econômica, social e as desigualdades regionais. Essa é uma condição essencial ao desenvolvimento socioeconômico.

Uma das questões conceituais que marcou este estudo foi precisamente a compreensão acerca da relação entre trabalho e desenvolvimento, por meio das transformações e exigências no decorrer do tempo. Para esclarecer as concepções teóricas discutidas no âmbito deste artigo, julgou-se conveniente analisar os condicionantes do desenvolvimento do mercado de trabalho, pois a economia reflete, em maior ou menor densidade, os aspectos vigentes em sociedade. O processo de continuidade do desenvolvimento econômico e a manutenção de postos de trabalho estão fundamentados nos pontos estruturantes da produção da riqueza, da renda e do fortalecimento do mercado de trabalho. 
Vislumbrou-se, neste artigo, que um dos fatores principais para o efetivo desenvolvimento socioeconômico é a criação de emprego, visto que a remuneração do trabalho permite a manutenção das condições essenciais à vida. Por esse meio, o trabalhador deve ter liberdade para exercer o consumo de produtos e serviços que lhe permitem não apenas sobreviver, mas exercer a plena cidadania, viver com atendimento à saúde, segurança física e social, moradia, educação e lazer próprio, bem como de seus familiares. Ou seja, que permitam tornar-se um ser social.

\section{Referências}

ANTUNES, Ricardo. A. Os Sentidos do Trabalho. São Paulo: Boitempo, 2009.

CASTEL. Robert. As metamorfoses da questão social: uma crônica do trabalho. Tradução de Iraci D.

Poleti. Petrópolis, RJ: Vozes, 1998.

DOBB, Maurice. A evolução do Capitalismo. 7 ed. Rio de Janeiro: Zahar Editores, 1980

FILHO, Milton B. B. História Moderna e Contemporânea. São Paulo: Scipione.1993.

FURET, François. Pensar a Revolução Francesa. São Paulo: Paz e Terra, 1989.

FURTADO, Celso. Introdução ao Desenvolvimento: enfoque histórico - estrutural. 3. ed. Rio de Janeiro: Paz e Terra, 2000.

FURTADO, Celso. O Mito do Desenvolvimento: enfoque histórico - estrutural. 3. ed. Rio de Janeiro: Paz e Terra, 1974.

FURTADO, Celso. Raízes do Subdesenvolvimento. Rio de Janeiro: Civilização Brasileira, 2005.

FURTADO, Celso. Uma política para o desenvolvimento do Nordeste. Novos Estudos CEBRAP, São Paulo, v. 1, 1, p. 12-19, dez. 1987.

GRESPAN, Jorge. Marx, crítico da teoria clássica do valor. Disponível em

$<$ https://www.ifch.unicamp.br/criticamarxista/arquivos_biblioteca/03gresp.pdf $>$ Acessado em abr. 2019.

HARVEY, David. O trabalho, o capital e o conflito de classes em torno do ambiente construído nas sociedades capitalistas avançadas, in Revista Espaço e Debates, nº 06, São Paulo: Cortez, jun./set. 1982.

HEGEL, G. W. F. Enciclopédia das Ciências Filosóficas em Compêndio: 1830. [tradução MENESES, Paulo] São Paulo, Loyola, 1995.

HUBERMAN, Leo. História da Riqueza do Homem. 17 ed. Rio de Janeiro: Zahar Editores, 1981.

KEYNES, A Teoria Geral do Emprego, do Juro e da Moeda, Os Economistas. São Paulo: Nova Cultural, 1988.

LESSA, Sergio. Lukács: trabalho, objetivação, alienação. Trans/Form/Ação, São Paulo, 15: 39-51, 1992.

LUKÁCS, György. Ontologia do ser social - O trabalho. Tradução de Ivo Tonet. A Foice e o Martelo, 2011.

MARX, Karl. A Ideologia Alemã. Trad. Rubens Enderle, Nélio Schneider e Luciano Cavini Martorano. São Paulo: Boitempo, 2007.

MARX, Karl. Contribuição à Crítica da Economia Política. Trad. Florestan Fernandes. São Paulo: Expressão Popular, 2008. 43

MARX, Karl. Introdução à Contribuição da Crítica da Economia Política. Trad. José Arthur Giannotti e Edgar Malagodi. (Coleção Os Pensadores). São Paulo: Abril Cultural, 1974.

MARX, Karl. Manuscritos Econômicos - Filosóficos. Trad. Jesus Ranieri. São Paulo: Boitempo, 2009. 
MARX, Karl. Miséria da Filosofia: resposta a Filosofia da Miséria, do Sr. Proudhon. Trad. José Paulo Netto. $1^{\text {a }}$ Ed. São Paulo: Expressão Popular, 2009.

MARX, Karl. O Capital: crítica da economia política. Livro I. Vol. VI. Trad. Reginaldo Sant'Anna. $3^{\mathrm{a}}$ edição. Rio de Janeiro: Civilização Brasileira, 2011.

MARX, Karl. O Capital: crítica da economia política. Livro II. Vol. VI. Trad. Reginaldo Sant'Anna. $3^{\text {a }}$ edição. Rio de Janeiro: Civilização Brasileira, 2011.

MARX, Karl. O Capital: crítica da economia política. Livro III. Vol. VI. Trad. Reginaldo Sant'Anna. $3^{\text {a }}$ edição. Rio de Janeiro: Civilização Brasileira, 2011.

MATTEI, Lauro. Teoria do valor-trabalho: do ideário clássico aos postulados marxistas. Ensaios FEE, Porto Alegre, v. 24, n. 1, p. 271-294, 2003.

PEDRÃO, Fernando. Economia, Política e Poder: Na periferia globalizada. Salvador: Editora JusPodivm, 2009.

POCHMANN, Marcio. Ajuste econômico e desemprego recente no Brasil metropolitano. Estudos Avançados 29 (85), 2015. Disponível em: < http://dx.doi.org/10.1590/S0103-40142015008500002>

POCHMANN, Marcio. ANTUNES, Ricardo. Alguns desafios do mundo do trabalho. São Paulo: Estudos Avançados, Nov. 2018.

POCHMANN, Marcio. Brasil: segunda grande transformação no trabalho? São Paulo: Estudos avançados 28 (81), 2014.

POCHMANN, Marcio. Desenvolvimento, trabalho e renda no brasil: Avanços recentes no emprego e na distribuição dos rendimentos. São Paulo: editora Fundação Perseu Abramo, 2010.

POCHMANN, Marcio. Economia global e a nova Divisão Internacional do Trabalho. Disponível em < http://decon.edu.uy/network/panama/POCHMANN.PDF> Acesso em novembro de 2018.

POCHMANN, Marcio. Educação e trabalho: Como desenvolver uma relação virtuosa? Educ. Soc., Campinas, vol. 25, n. 87, p. 383-399, maio/ago. 2004.

POCHMANN, Marcio. MORAES, Reginaldo. Classe trabalhadora e luta política capitalismo, no início do século XXI. São Paulo, Jul. 2017.

POCHMANN, Marcio. O Emprego no Desenvolvimento da Nação. Rio de Janeiro: Boitempo Editorial, 2008.

QUINTANEIRO, Tania. Um Toque de Clássicos: Marx, Durkheim e Weber. Belo Horizonte: UFMG, 2003.

ROSSI, Luiz Alexandre Solano. Modo de Produção Escravista e a Sua Influência na Percepção da Sociedade Judaica no Pós-Exílio. In: COSTA, Ricardo da. Mirabilia. Jun-Dez 2005/ISSN 1676-5818. Disponível em: <https://www.revistamirabilia.com/sites/default/files/pdfs/2004_03.pdf>

SANTOS, Milton. O Espaço Dividido: os dois circuitos da economia urbana dos países subdesenvolvidos. Rio de Janeiro: Francisco Alves Editora S.A., 1979.

SANTOS, Milton. Por uma outra Globalização. São Paulo: Editora Record, 2000.

SEN, Amartya. Desenvolvimento como Liberdade. São Paulo: CIA Letras, 2010.

SINGER, Paul. Globalização e Desemprego: diagnósticos e alternativas. São Paulo: Contexto, 1999.

SMITH, Adam. A Riqueza das Nações: Uma investigação sobre a natureza e as causas da riqueza das nações. São Paulo: Masdras, 2009.

WEBER, Max. Conceito e categorias da cidade In: VELHO, Otávio Guilherme. O fenômeno Urbano. Rio de Janeiro, 1967. 